\title{
De Ascomyceet, Kerbertia oniscidarum nov. gen. nov. spec. in den darm van eenige 0nisciden
}

\author{
DOOR
}

\author{
Dr. MIA BOISSEVAIN
}

(met plaat VIII en IX).

Toen ik ongeveer vier jaar geleden, bezig was aan een onderzoek over de spermatogenese van Oniscus murarius en Porcellio-soorten, viel het mij op, dat bij een aantal dieren de einddarm vol zat met talrijke, op de sporenbuisjes van een of andere Ascomyceet gelijkende lichaampjes. Deze sporenbuisjes, of asci, bevonden zich in allerlei stadien van groei; van kort met ongedifferentieerden celinhoud, tot lang met uiterst talrijke (tot over de 100) mooie goed gevormde, aan twee kanten eenigszins toegespitste sporen. Ze zaten losjes vastgehecht, ieder afzonderlijk, schots en scheef tegen den binnenwand van den einddarm, zonder dat verder van eenig substratum of samenhang der sporenbuisjes onderling iets te bemerken viel. Het scheen wel alsof tengevolge van de parasitische levenswijze in den darm van het dierlijk organisme, er van den fungus niets anders was overgebleven dan de asci, die dan het begin en het einde van zijn levenscyclus zouden vormen, altijd natuurlijk in geval er geen andere ontwikkelingsstadien buiten den gastheer zouden bestaan. Naderhand bleek mij evenwel, dat bij alle door den fungus aangetaste dieren ook eigenaardige weefselwoekeringen vlak bij het anale gedeelte van den einddarm voorkwamen, woekeringen die ongetwijfeld uitgaan van de darmepitheelcellen en de omringende weefsels, maar ook in nauw verband staan met de vegetatieve ontwikkeling van den fungus.

De dieren die ik voor mijn onderzoek gebruikte waren afkomstig uit mijn tuin te Bilthoven. Sedert het eerste aantreffen van de zwam in het najaar 1914, heb ik haar ieder jaar opnieuw bij versch gevangen, zoowel als in gevangenschap opgekweekte dieren aangetroffen. Bovendien bleek mij, dat Oniscus murarius en Porcellio-soorten verzameld te Amsterdam, Aerdenhout, den Helder, Naarden en Hattem die zelfde eigenaardige asci in den einddarm vertoonden.

Het blijkt dus, dat het hier niet gold een toevallige plaatselijke en tijdelijke infectie, maar dat men hier te doen heeft met een nieuw geval van een, in een dierlijk organisme parasiteerenden fungus, die voor zoo ver kon worden nagegaan een tamelijke verbreiding in ons land heeft. Het is door de tegenwoordige tijdsomstandigheden natuurlijk niet mogelijk een onderzoek naar het voorkomen over uitgestrektere gebieden in te stellen.

Pogingen in 't najaar 1914 ondernomen, om van deze zwam een reinkultuur te maken hadden voorloopig nog geen succes. Hoewel een aantal verschillende voedingsbodems werden aangewend, kiemden de sporen niet, maar het kwam mij voor, dat de herfst ook niet de beste tijd is om een kultuur aan te vangen, daar de fungus dan aan het einde van een ontwikkelingsperiode staat. Men vindt in de maanden November, December en Januari 
maar weinig dieren met ascosporangiën in den einddarm; ze zijn bij de laatste vervelling van het dier, waaraan ook de binnenwand van den darm deelneemt mede naar buiten getreden. In Februari en Maart begint het aantal geinfecteerde dieren weer toe te nemen, om ongeveer in September het hoogtepunt te bereiken.

De darm der Onisciden bestaat uit regelmatige rijen groote epitheelcellen, die volgens SchöNıchen 1) niettegenstaande zij duidelijke celvorm vertoonen, te samen een syncytium zouden vormen. Zij bevatten groote, half vloeibare kernen, die om de veranderingen die zij bij een verminderde osmotische spanning ondergaan interessant zijn om waar te nemen. Naar binnen toe zonderen die epitheelcellen een tamelijk stevige doorschijnende chitinemembraan af. Deze tunica intima, product dus der epitheelcellen, is uiterst fijn en regelmatig geperforeerd. Het is tegen dezen chitineusen binnenwand van den darm in het rectale gedeelte, en ook wel iets meer naar den middendarm toe, dat de ascosporangiën worden aangetroffen. Fig. 10 Plaat $V$ geeft een stukje van den darmwand te zien, gezien van de binnenzijde. De epitheelcellen liggen onder de doorzichtige chitineuse membraan, waarop de talrijke asci bevestigd zijn. Deze zitten op een zeer kleine verhevenheid van de. membraan, het basale gedeelte in een propje slijm gedoken. Van eenige regelmaat of rangschikking in de ligging is niets te bespeuren, wel ziet men af en toe in een darmplooi de asci aan beide zijden op rijen geplaatst, maar iets verder liggen zij dan weer schots en scheef door elkander. Een volledige en nauwkeurige beschrijving dezer merkwaardige ascosporangiën met hun sporen zou ik liever willen uitstellen tot het gelukt is deze zwam in kultuur te krijgen. Eenige korte mededeelingən mogen hier ter plaatse volstaan.

De asci die men in den zomer aantreft zijn bij rijpheid van $\pm 100 \mu$ tot $250 \mu$ groot. Zij loozen de sporen slechts bij enkelen te gelijk, zoodat men dikwijls asci aantreft aan welker uiteinden rijpe sporen bezig zijn naar buiten te treden, terwijl aan de basis van den ascus de celinhoud nog niet in afzonderlijke sporen is afgescheiden. De loskomende sporen zijn week en waarschijnlijk kleverig en hechten zich gemakkelijk aan den darmwand in de omgeving van den ouden ascus of blijven bij troepjes in een darmplooi opgehoopt. In den voorzomer zijn de sporen vaak tweekernig terwijl zij in den nazomer' over 't algemeen eenkernig zijn, doch ik heb tot mijn spijt dat punt niet nauwkeurig nagegaan. In October en November vindt men nog een andere soort ascosporangien, die ongeveer 3 à 4 maal zoo lang zijn als de vorigen. Ze liggen meestal iets hooger op, tot zelfs in den middendarm. Zij bevatten tot over de honderd mooie, goedgevormde, aan twee kanten eenigszins toegespitste glimmende sporen, die allen gelijktijdig rijp zijn en soms tot op twee rijen saamgedrongen zijn. (fig. 9). Deze ascosporangiën treft men slechts zelden aan en dan nog wel alleen laat in 't najaar, men zou ze wintersporangiën kunnen noemen, ze kunnen wäarschijnlijk in het voorjaar een nieuwe infectie der dieren te weeg brengen. Het is duidelijk, dat de sporen die des zomers uit de zomersporangiën te voorschijn treden, dadelijk weer tot nieuwe asci kunnen uitgroeien. De einddarm, eenmaal van ascosporangiën voorzien, besmet zich zelve voortdurend weer. Stadiën waar men de sporen uit de asci te voorschijn ziet treden en vervolgens een aantal pas aangehechte sporen in verschillende grootte rondom de rijpe asci ziet liggen, komen veelvuldig voor. De groei van deze asci heeft dus klaarblijkelijk plaats door rechtstreeksche opname der darmvloeistoffen. Dat zij nl. daar ter plaatse met eenig weefsel van de zwam in directe verbinding zouden staan acht ik uitgesloten. Veel meer heeft men hier te doen met losse, vrijstaande ascosporangiën die als gevolg van hun parasitische levenswijze het verband met hun moederbodem verloren hebben. De vraag is nu, hoe komen deze ascosporangiën oorspronkelijk in den darm. Voor een antwoord op die vraag is het noodig de vegetatieve en verdere ontwikkeling van de zwam te leeren kennen. De vegetatieve ontwikkeling geeft aanleiding tot eenige zeer interessante vormveranderingen van den einddarm. Het heeft mij betrekkelijk veel tijd gekost om achter de anatomische bizonderheden van die weefselwoekeringen te komen, daar men meestal bij het uitprepareeren van den darm het

1) W. Scrö̈richev, Der Darmkanal der Onisciden und Aselliden. Zeitschrift f. Wissensch. Zool. Bd. 65. 
rectale gedeelte en de woekeringen aldaar grootendeels scheurt. Toch gelukt het soms, eenige in toto vrij te krijgen waardoor het mij mogelijk werd een inzicht in de verhoudingen te krijgen. Het bleek n.l. dat bij de aangetaste dieren het rectale gedeelte van den darm zeer dikwijls aan de ventrale zijde overlangs gespleten is. De darminhoud zou hier in de lichaamsholte kunnen treden indien niet de spierlaag in de meeste gevallen voor de afsluiting zorgde, maar tevens woekert uit een meer proximaal gelegen spierbundel, eveneens aan de ventrale zijde van den darm, een eigenaardig plat kelkvormig uitgroeisel, welks randen met de spierbundellaag vergroeid kunnen zijn en zich naar achteren toe over de darmspleet heenbreidt. De verhoudingen zijn hier moeilijk waar te nemen, daar de spieren bij het anale gedeelte van den darm sterk hypertrophisch zijn geworden en de spiervezellaag, waarmede het aanhangsel vergroeid kan zijn, in de meeste gevallen scheurt, zoodat dit laatste vrij komt te hangen en onder het microscoop den indruk makkt van een klein ventraal aanhangsel van den darm dat vrij in de lichaamsholte hangt. Dit is in de beginstadiën van het aanhangsel ook werkelijk het geval en het schijnt mij toe dat het in latere stadiën secundair met de spiervezellaag vergroeid kan raken. Meermalen ziet men aan den voet van het aanhangsel op de plaats waar het bij de ventrale spier te voorschijn treedt, nog een kleiner en soms zelfs een derde nog weer kleinere aanleg van een uitgroeisel, (fig. 1 en 2). Ik houd het er dan ook voor dat na iedere vervelling een nieuw uitgroeisel de plaats van het oude, dat dan zijn functie vervuld heeft, komt vervangen.

Dit kelkvormige aanhangsel is evenwel volstrekt niet datgene wat het meest opvalt bij een onderzoek van den einddarm. Integendeel het duurde geruimen tijd voor ik het ontdekt had, terwijl daarentegen dadelijk veel meer in het oog springt de aanwezigheid van een rand verdikt darmepitheel waardoor heen zich zeer waarschijnlijk de myceliumdraden gevlochten hebben.

T'en einde nu een duidelijke voorstelling te kunnen geven van hoe en waar deze epitheelwoekeringen plaats vinden, moet ik er aan herinneren, dat bij de vervelling ook de geheele binnenwand van den darm wordt afgestroopt. Niet zelden komt het voor, dat men den chitineusen binnenwand gemakkelijk in haar geheel met het pincet uit den darm kan te voorschijn halen (fig. 2). Bij nauwkeurige beschouwing bemerkt men dan dat die membraan op eenigen afstand van de anale opening een licht gegolfde ringvormige teekening vertoont, waarschijnlijk teweeg gebracht door een geringe plaatselijke verdikking van de chitinemembraan. Bij zeer sterke vergrooting kan men nu bij Porcellio-soorten (bij Oniscus murarius was dit niet het geval) waarnemen, dat het gedeelte van de chitinemembraan, dat distaal van dien ring ligt, aan de binnenzijde voorzien is van uiterst fijne tandjes, die in de rangschikking veel overeenkomst vertoonen met die op de huid alleen maar veel minder ontwikkeld zijn. Deze tandjes duiden er m.i. op, dat men hier met een ectodermaal gedeelte van den darm te doen heeft. Wat de oorsprong van de rest van den darm betreft, schijnt men daarover bij Onisciden nog eenigszins in onzekerheid te verkeeren. Ik houd het evenwel voor zeer waarschijnlijk, dat de bovengemelde chitineverdikking de plaats aanduidt waar twee celwerelden elkander begrenzen. Ook de epitheelwoekeringen door den fungus veroorzaakt, komen deze opvatting versterken. Het is n.l. juist op deze grens, dat die epitheelverdikkingen voorkomen en wel zijn het de epitheelcellen van het darmgedeelte dat proximaal van den chitineusen ring ligt, die een aantal pathologische deelingen doormaken, waarbij de cellen met hun kernen telkens kleiner worden tot zij eindelijk een samengedrongen band van onregelmatig cylinderepitheel vormen, dat in lichte golvingen naar binnen omkrult, juist op de plaats waar naderhand de chitine verdikking zichtbaar zal blijven (fig. 1, 6, 7 en $10 \mathrm{ep}$. w.). Die epitheelwoekeringen zijn dan aan de darmlumenzijde door de chitineuse tunica intima bedekt. Distaal gaat de woekering over in een dunne membraan, die uit kleinkernige cellen is opgebouwd en die voortwoekert tusschen de tunica intima en de darmepitheelcellen. Aan de ventrale zijde van den darm, op de plaats waar de overlangsche splijting van den darmwand tot stand komt, woekert dit pathologische epitheel aan weerszijden van de spleet naar achteren toe en nestelt zich hier dus ook tegen dat deel der tunica intima, 
dat van ectodermatischen oorsprong is. Het kan zich dan bij zijn verdere ontwikkeling in een aantal bochten wringen, waardoor dikwijls een overzicht van het geheel bemoeilijkt wordt. De ascosporangien bevinden zich nu steeds in groote massa's in dat gedeelte van den einddarm, dat proximaal van den verdikten intimarand ligt. $0 p$ het achterste, ectodermale gedeelte, waarop de minutieuse huidtandjes zichtbaar zijn, vindt men wel sporadisch hier en daar een enkel sporangium vastgehecht, doch dit blijft tot de uitzonderingen behooren.

Ik heb hier-in 't kort de voorstelling weergegeven, die ik mij na een langdurig vergèlijkend onderzoek van de feiten heb gemaakt: De toestand varieert in werkelijkheid nog al. In enkele gevallen is het spierweefsel zoo hypertrophisch geworden, dat men haast niet anders dan spieren onderscheiden kan. Soms is de overlangsche ventrale darmspleet duidelijk zichtbaar - soms ternauwernood of heelemaal niet te zien. Soms is het kelkvormig aanhangsel flink ontwikkeld, soms slechts aanwezig als een klein uitwasje aan de voet van de spier. Soms bepaalt zich. de epitheelwoekering alleen tot de cirkelvormige grens waar ' $t$ ectoderm begint, soms is het in hooge mate ontwikkeld en in allerlei bochten gewrongen; of ook gebeurt het wel, dat de darm zich als een afgestroopte handschoenvinger over het geheel heenstulpt en door spierweefsel aan alle zijden vergroeid raakt, zoodat een onduidelijk kluwen van weefsels gevormd wordt.

Deze ongelijkheid van voorkomen kan grootendeels verklaard worden uit het feit, dat de zwam zich des zomers in alle mogelijke stadien van ontwikkeling bevindt, al naarmate er juist een vervelling heeft plaats gehad of nog moet plaats hebben. Ook is het een groot verschil of men met jonge of oude dieren te doen heeft. Zeer jonge dieren, niet grooter dan 2 à 3 mM., hebben soms den einddarm geheel gevuld met ascosporangiën, zonder dat men evenwel van een sterke hypertrophie, vooral van het spierweefsel in het anale gedeelte iets bemerken kan. Ik heb nooit nagegaan hoe oud pissebedden kunnen worden, maar ik veronderstel, dat zij minstens 3 à 4 jaar oud kunnen worden. $1 k$ vermoed dat bij een. dier, dat eenmaal geinfecteerd werd, telkens na iedere vervelling een nieuw kelkvormig aanhangsel kan uitgroeien, dat dan weer nieuwe generatiereeksen van asci in den darm doet ontstaan.

Het is zeer moeilijk na te gaan op wat voor wijze de myceliumdraden met het dierlijk celweefsel zijn verbonden. Het mocht mij niet gelukken langs microchemischen weg de draden te zien te krijgen. Wanneer men met tamelijk sterk pikrienazijnzuur den darm fixeert verliezen de epitheelwoekeringen in korten tijd hun spanning. Men ziet nog eenigen tijd de langwerpig samengedrukte kernen der epitheelcellen op onregelmatige rijtjes naast elkander liggen, doch bij den minsten druk wijken de cellen uit elkaar.

Het komt mij voor dat het epitheelweefsel geheel ineengevlochten is met de funguscellen. Ook het vliezige celweefsel, dat van de epitheelbanden tusschen de tunica intima en de darmcellen distaal voortwoekert, lijkt mij uit funguscellen te bestaan. In die cellaag (fig. 1; 6 , 9 en $10 \mathrm{vl}$.) ziet men duidelijke fijne celwanden, de kernen zijn goed zichtbaar en deze cellen zijn evenmin bestand tegen sterk azijnzuur.

Het allermoeilijkste is na te gaan uit wat voor cellen het ventrale aanhangsel is opgebouwd. Aan den ventralen darmwand ligt een vleugelvormige spier (fig. 1 en $\%$ sp.). In achterwaarsche richting precies op de middellijn groeit daaruit het aanhangsel (fig. 1 en 7 aanh.). Soms is een deel der vleugelvormige spieren vergroeid tot een eigenaardig napje, waaruit dan de bandvormige steel van het aanhangsel te voorschijn treedt. Daarnaast ziet men dan soms de jongeré aanhangsels op komst. Dat de myceelảraden hier zeer nauw verbonden zijn met de spieren, is zeer waarschijnlijk. Men vindt soms individuen waar de spieren van den einddarm alle overgangen van hypertrophie tot algeheele degeneratie vertoonen. Het kelkvormig aanhangsel bestaat zelve uit cellen met kleine kernen en een dieper inwendig gedeelte dat zich door de gebruikelijke aniline kleurstoffen niet laat kleuren. Bij het losscheuren schrompelen de randen eenigszins naar binnen, waardoor het inwendige niet duidelijk meer -is waar te nemen. Soms vindt men stadiën als in fig. 8, waarbij de kernen op regelmatige rijen achter elkaar liggen, gescheiden door fijne membranen. Ook treft men vaak in de kelkvormige holte een kleverige slijmprop aan. Dat de buitenzijde van het aanhangsel 
จ. n. uit dierlijk weefsel bestaat, terwijl het inwendig gedeelte uit.funguscellen is opgebouwd, acht ik wel waarschijnlijk.

Ik houd het er dan ook voor, dat dit aanhangsel, wanneer het zich over de ventrale spleet van het rectum heenspreidt, de infectie van den darm met sporen, die tot asci, uitgroeien, kan bewerkstelligen. Het blijft evenwel een veronderstelling, doch het uiterlijk der cellen in de kelk doet mij wel gelooven in de mogelijkheid, dat zij afgesnoerd kunnen worden in de vorm van eenkernige sporen. Het lijkt misschien eenigszins vreemd, dat deze sporen zoo zij inderdaad uit het kelkvormig aanhangsel afgesnoerd worden, in proximale richting een weg in den darm zouden vinden, doch bij de beschouwing van fig. 7 zal men moeten erkennen, dat dit bezwaar niet heel groot is, te meer omdat bij de talrijke spiercontracties van den einddarm de sporen gemakkelijk naar het darmgedeelte, dat vóór de chitineuse verdikking ligt, gestuwd kunnen worden en de sporen, eenmaal daar aangeland, door de plooien der epitheelverdikkingen belet worden naar achteren weg te stroomen.

Nieuwe infectie van gezonde dieren heeft hoogstwaarschijnlijk plaats bij de voedselopname door den mond. Bij de eenmaal geinfecteerde dieren kan na iedere vervelling een nieuw ventraal aanhangsel nitgroeien, dat een nieuwe generatie sporen afzondert, die een nieuwe reeks van opeenvolgende generaties van asci het aanzijn geven. Een nader botanisch onderzoek van deze merkwaardige fungus is zeker nog gewenscht.

Gaarne wil ik hier dank brengen aan Prof. Johanna Westerdijk, die mij bij het botanisch gedeelte van dit onderzoek raad verschafte en mij bij mijn pogingen om deze zwam in kultuur te. brengen gastvrijheid verleende op het Phytopathologisch Laboratorium te Amsterdam. In de mycologische litteratuur is deze zwam niet bekend, en ook in de talrijke zoologische geschriften heb ik geen mededeeling over het voorkomen aangetroffen. Waar ik dus het voorrecht heb. een ' naam aan dezen nieuwen Ascomyceet te mogen geven, zou ik daaraan gaarne de herinnering willen verbinden aan onzen algemeen geachten en beminden Directeur van "Artis", Dr. C. Kerhert, ter wiens eere deze feestbundel is samengesteld en deze zwam daarom Kerbertia willen noemen. Aan den geslachtsnaam Kerbertia zij dan de soortsnaam oniscidarum toegevoegd.

Hoe schijnbaar nietig ook het voorwerp moge wezen waarorer Dr. Kerbert nu het peetschap gaat aanvaarden, de bioloog ziet in gedachten meer dan het enkele voorwerp. In gedachten blikt hij terug op lange tijdperken van duister verleden, waarin Kerbertia oniscidarum met wisselende kansen haar strijd om bestaan voerde en vragend blijft hij stilstaan bij het raadsel van haar oorspronğ, om dan den blik te wenden naar de komende tijdperken waarin dit organisme zal blijven doorgaan met zich voort te planten en hij beseft, dat hij het raadsel van haar biologisch einde of misschien ook wel biologische toekomst al evenmin benaderen kan. 


\section{PLATENVERKLARING.}

aanh. = kelkvormig aanhangsel.

ep.w. = epitheelwoekering.

vl. = vlies.

ch. $\mathrm{m} .=$ chitineuse membraan.

$$
\begin{aligned}
\text { asc. } & =\text { ascosporangiën } \\
\text { sp. } & =\text { spier. } \\
\text { t. } & =\text { tandjes. }
\end{aligned}
$$

\section{PLAA'T VIII.}

Fig. 1. Gedeelte van den eindarm van Oniscus murarius van de ventrale zijgde gezien. De plaats, waar het kelkvormig aanhangsel aan den voet der vleugelvormige spieren ontspruit en in distale richting over de ventrale darmspleet hangt.

Fig. 2. Rectaal gedeelte van de chitineuse darmmembraan die bij de vervelling wordt afgestroopt, met daarin nog aanwezige ascosporangiën. De grens, waar het met tandjes bezette gedeelte begint, is duidelijk zichtbaar. Porcellio sp.

Fig. 3. Einddarm der Onisciden van de dorsale zijde gezien, gevuld met ascosporangiën.

Fig. 4. Einddarm, ventrale zijde, met kelkvormig aanhangsel.

Fig. 5. Einddarm, zijdelings.

Fig. 6. Optische doorsnede van de plaats waar de darmepitheelcellen beginnen te woekeren en te samen met de funguscellen zich tot een vlies uitbreiden tusschen darmepitheel en chitineuse membraan.

\section{PLAAT IX:}

Fig. \%. Einddarm van Porcellio sp. opgevuld met ascosporangiën. Een stuk van den ven: tralen darmwand is zichtbaar met de vleugelvormige spieren, aan welke basis het kelkvormig aanhangsel ontspruit.

Fig. 8. Kelkvormig aanhangsel van Oniscus murarius, in een betrekkelijk zeldzaam stadium.

Fig. 9. Een wintersporangium.

Fig. 10. Een stuk van den einddarm van Porcellio sp. van de binnenzijde gezien. 


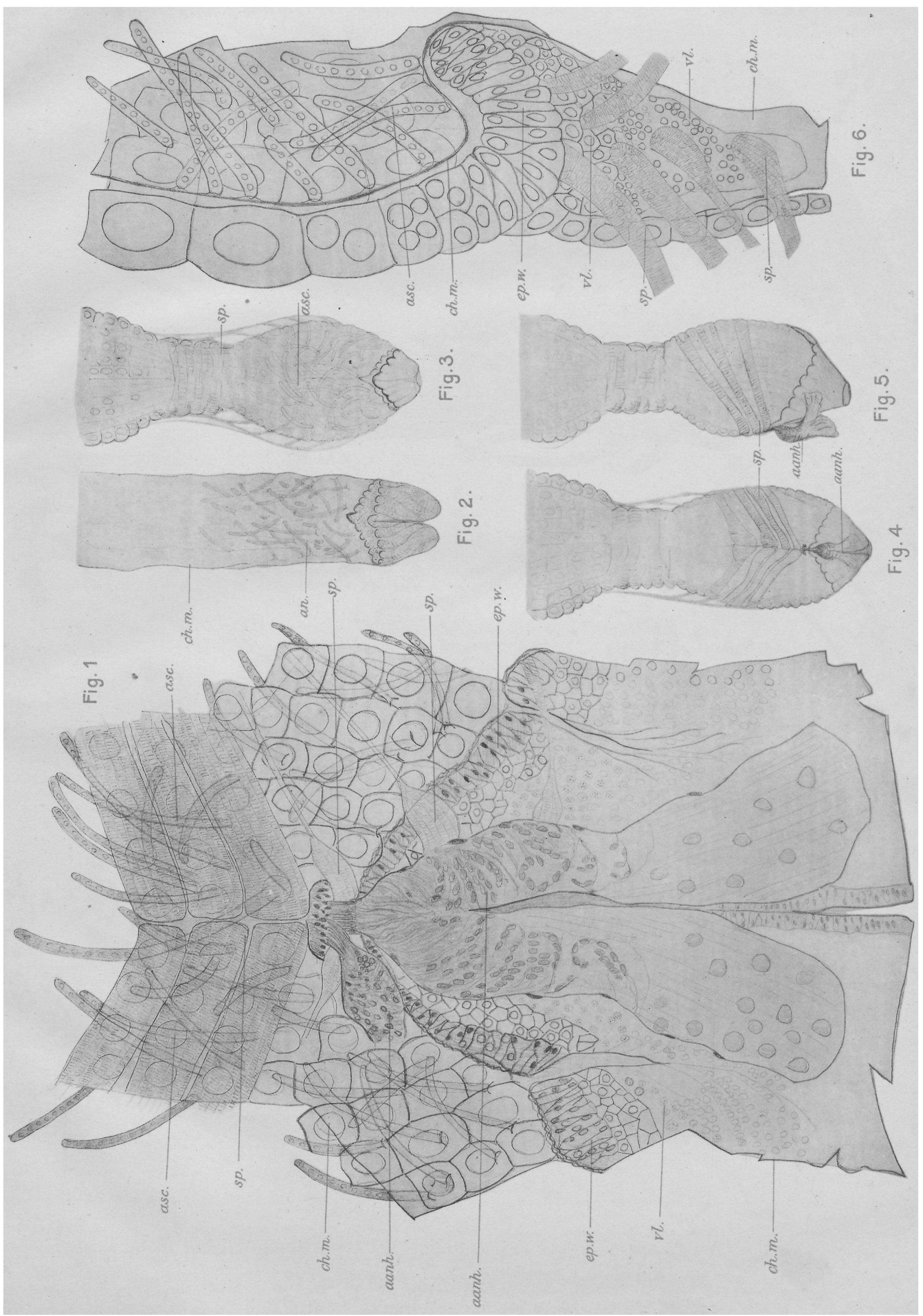




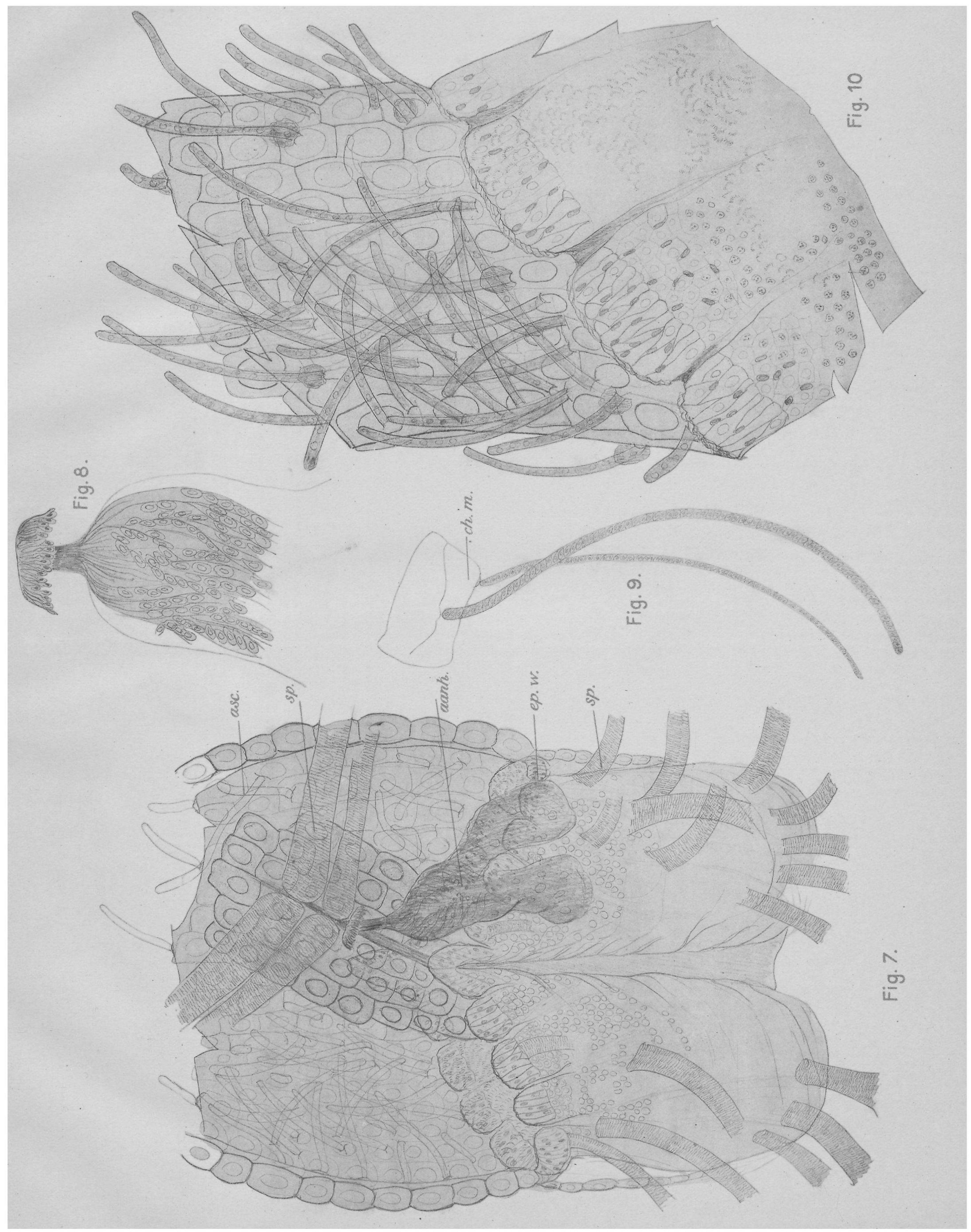

